\title{
General lifestyle interventions on their own seem insufficient to improve the level of physical activity after stroke or TIA: a systematic review
}

Wendy Hendrickx ${ }^{1,2^{*}}$, Lara Vlietstra ${ }^{3}$, Karin Valkenet ${ }^{1}$, Roderick Wondergem ${ }^{1,2,4}$, Cindy Veenhof ${ }^{1,2,5}$, Coralie English ${ }^{6,7}$ and Martijn Frits Pisters ${ }^{1,2,4}$

\begin{abstract}
Background: Insufficient amounts of physical activity is a risk factor for (recurrent) stroke. People with a stroke or transient ischemic attack (TIA) have a high risk of recurrent stroke and have lower levels of physical activity than their healthy peers. Though several reviews have looked at the effects of lifestyle interventions on a number of risk factors of recurrent stroke, the effectiveness of these interventions to increase the amounts of physical activity performed by people with stroke or TIA are still unclear. Therefore, the research question of this study was: what is the effect of lifestyle interventions on the level of physical activity performed by people with stroke or TIA?

Method: A systematic review was conducted following the guidelines of the Preferred Reporting Items for Systematic Reviews and Meta-analyses (PRISMA) statement. Pubmed, Embase and Cumulative Index for Nursing and Allied Health Literature (CINAHL), were searched up to August 2018. Randomised controlled trials that compared lifestyle interventions, aimed to increase the amount of physical activity completed by participants with a stroke or TIA, with controls were included. The Physiotherapy Evidence Database (PEDro) score was used to assess the quality of the articles, and the Grading of Recommendations, Assessment, Development and Evaluations (GRADE) method for the best evidence synthesis.
\end{abstract}

Results: Eleven trials $(n=2403)$ met the inclusion criteria. The quality of the trials was mostly high, with $8(73 \%)$ of trials scoring $\geq 6$ on the PEDro scale. The overall best evidence syntheses showed moderate quality evidence that lifestyle interventions do not lead to significant improvements in the physical activity level of people with stroke or TIA. There is low quality evidence that lifestyle interventions that specifically target physical activity are effective at improving the levels of physical activity of people with stroke or TIA.

(Continued on next page)

\footnotetext{
* Correspondence: W.Hendrickx@umcutrecht.nl;WHendrickx@lrjg.nl

'Department of Rehabilitation, Physiotherapy Science \& Sport, UMC Utrecht Brain Center, University Medical Center Utrecht, Utrecht University, Utrecht, The Netherlands

${ }^{2}$ Center for Physical Therapy Research and Innovation in Primary Care, Julius

Health Care Centers, Emile Hullebroeckstraat 60, 3543 BZ Utrecht, The Netherlands

Full list of author information is available at the end of the article
}

(c) The Author(s). 2020 Open Access This article is licensed under a Creative Commons Attribution 4.0 International License, which permits use, sharing, adaptation, distribution and reproduction in any medium or format, as long as you give appropriate credit to the original author(s) and the source, provide a link to the Creative Commons licence, and indicate if changes were made. The images or other third party material in this article are included in the article's Creative Commons licence, unless indicated otherwise in a credit line to the material. If material is not included in the article's Creative Commons licence and your intended use is not permitted by statutory regulation or exceeds the permitted use, you will need to obtain permission directly from the copyright holder. To view a copy of this licence, visit http://creativecommons.org/licenses/by/4.0/ The Creative Commons Public Domain Dedication waiver (http://creativecommons.org/publicdomain/zero/1.0/) applies to the data made available in this article, unless otherwise stated in a credit line to the data. 
(Continued from previous page)

Conclusion: Based on the results of this review, general lifestyle interventions on their own seem insufficient in improving physical activity levels after stroke or TIA. Lifestyle interventions that specifically encourage increasing physical activity may be more effective. Further properly powered trials using objective physical activity measures are needed to determine the effectiveness of such interventions.

Trial registration: PROSPERO, CRD42018094437.

Keywords: Stroke, Lifestyle, Risk reduction behaviour, Secondary prevention, Exercise

\section{Background}

Cardiovascular disease is the leading cause of death and disability globally [1]. Cerebrovascular diseases, including stroke and transient ischemic attack (TIA), account for $34 \%$ of cardiovascular disease in males and $37 \%$ in females [1]. This equates to approximately 15 million people worldwide having a stroke or TIA each year [1]. Due to improvements in acute stroke treatment, survival rates are improving in several parts of the world [1]. However, people who have had a stroke or TIA are at high risk (40\% in 10 years) of having a recurrent stroke $[2,3]$. Therefore, secondary prevention is vital.

Insufficient levels of physical activity is one of the strongest modifiable risk factors of stroke and recurrent stroke [1, 4, 5]. The World Health Organisation, the American Heart Association and the American Stroke Association recommend 150 min per week of moderateintensity aerobic activity or 75 min per week of vigorous aerobic activity, or a combination of both, preferably spread throughout the week and preferably performed in bouts of at least $10 \mathrm{~min}$ duration [6-8]. However, recent studies have shown that the levels of physical activity performed by people with a stroke or TIA do not meet these recommendations and are low compared to the physical activity levels of healthy peers [9-11]. Thus, it appears that people with stroke and TIA require additional interventions to support them to improve their level of physical activity.

Several multimodal lifestyle interventions have been developed, incorporating educational, motivational and other psychosocial components with the aim to support behaviour change to reduce risk factors of recurrent stroke, including improving physical activity levels for people after stroke or TIA. Since improving physical activity is recommended in Stroke Clinical Guidelines internationally [12-15], it is important to know if these lifestyle interventions are effective in order to guide clinical practice. Three earlier similar reviews have been conducted. The first review only included trials published up to 2009 [16], and found insufficient evidence to determine the effects of lifestyle interventions on the levels of physical activity. The second review was also inconclusive [17], both recommend further high quality research $[16,17]$. The most recent review [18], including trials published up to May 2015, concluded that a metaanalyses on physical activity was not possible due to diversity in the outcome measures used [18]. A best evidence synthesis including comparison of the intervention effect to controls and weighing the quality of the included trials was not conducted nor was an effect estimate of the interventions provided [18]. It remains unclear if lifestyle interventions are effective in improving the levels of physical activity performed by people with stroke or TIA. Furthermore, the need to include strategies that specifically focus on the levels of physical activity, e.g. supervised exercise, is unclear. A review specifically examining the effects of lifestyle interventions on physical activity after stroke is needed to support physiotherapists' clinical practice. Therefore, the research question for this systematic review was: What is the effect of lifestyle interventions on the level of physical activity performed by people with stroke or TIA?

\section{Methods}

This systematic review was conducted in accordance with the guidelines of the Preferred Reporting Items for Systematic Reviews and Meta-Analyses (PRISMA) statement [19], and is registered with the International Prospective Register of Systematic Reviews (PROSPERO; CRD42018094437).

\section{Eligibility criteria}

Trials were eligible for inclusion if:

1) the participants were adults with clinically confirmed stroke or TIA;

2) the intervention was a lifestyle or behavioural intervention, defined as an intervention that incorporated educational, motivational and other psychosocial components with the aim to support behaviour change to reduce risk factors of recurrent stroke;

3) the study design was a randomised clinical trial (RCT) where the lifestyle intervention was compared with 'no intervention', 'placebo' and/or 'usual care'; 
4) at least one outcome measure of physical activity (any form of light physical activity and/or moderate to vigorous physical activity) was reported;

5) the full text article was available in English or Dutch.

Trials defined in the manuscript as a pilot or feasibility trial were excluded because of likely insufficient power to show effect.

\section{Search}

Three electronic databases, Pubmed, Embase and CINAHL, were searched up to August 2018. The search strategy was constructed in Pubmed and adapted for CINAHL and Embase, see supplementary Additional file 1 ('Search Strategy') for the search strategy. We also scanned reference lists of relevant previous reviews identified in the initial orientation search and in the systematic search, for any additional relevant citations [16-18].

\section{Study selection}

All trials identified in the search were first screened by title and abstract, then full-texts reviewed to determine eligibility. The study selection was independently conducted by the 2 authors (WH and LV). Disagreements were resolved by discussion. If no consensus could be reached, a third author (MFP) was consulted.

\section{Data extraction}

Data extraction included descriptive data, demographics of study populations, sample sizes, the content of the intervention and the control, duration of the intervention, outcome measures on physical activity, time points of measurement and the study results. Data were extracted by one author (WH) and checked by a second author (LV) with disagreements resolved by discussion. If no consensus could be reached a third author (MFP) was consulted.

\section{Quality appraisal}

The PEDro scale for RCTs and controlled clinical trials was used to determine the methodological quality of the included trials [20]. The PEDro scale consists of 11 'yes' or 'no' statements with regards to domains like randomisation, blinding, attrition and reporting of results (see supplementary Table S1, PEDro scale). Points are only awarded when a criterion is clearly satisfied [20]. The highest possible score is 10 points (item 1 is not scored) [20]. Trials with a total score of 6 or higher are considered to be of high quality [21]. The quality appraisal was independently completed by 2 authors (WH and LV). The results were compared to see if there were any differences. If so, these were discussed. If no consensus could be reached a third author (MFP) was consulted.

\section{Best evidence synthesis}

A meta-analysis was the preferred synthesis method. However, due to heterogeneity of outcome measures in the different trials, this was not possible. Instead, a best evidence synthesis was conducted, based on the available results from the included trials. We used the best evidence synthesis method from the Grading of Recommendations, Assessment, Development and Evaluations (GRADE) Working Group [22-25]. This method combines the consistency of the findings with the quality of the included trials. The domains for high quality evidence are [22-25]:

1) At least $75 \%$ of the RCTs with no limitations of study design have consistent findings,

2) Direct data, (this refers generalisability, the extent to which the people, interventions and outcomes in the trials are comparable to those defined in the inclusion criteria of the review).

3) Precise data, (this refers to a sufficient number of participants and events and the width of the confidence intervals).

4) No known or suspected publication biases.

For each domain for 'high quality evidence', that is not met, the level of evidence is downgraded [22-25]:

- High quality evidence: At least $75 \%$ of the RCTs with no limitations of study design have consistent findings, direct and precise data and no known or suspected publication biases;

- Moderate quality evidence: 1 of the above domains is not met;

- Low quality evidence: 2 of the above domains are not met;

- Very low quality evidence: 3 of the above domains are not met.

\section{Effect size of the intervention and subgroup analyses}

To determine the effect size of the interventions, the standardized mean difference (SMD), including the 95\% confidence intervals, was calculated where possible for the between group differences at follow-up [26]. A SMD of $\geq 0.2$ was considered a small effect, $\geq 0.5$ a moderate effect, and $\geq 0.8$ a large effect of exercise therapy as stated by Cohen et al. [27]. Subgroup analyses were performed based on the content of the intervention, i.e. the inclusion of specific strategies targeting improving the level of physical activity in people with stroke or TIA.

\section{Results}

Flow of trials through the review

A total of 8245 articles were identified in the literature search. When duplicates were removed, 7986 articles 
remained. After screening the titles and abstracts, 35 articles progressed to full text review, of which 11 trials were included (Fig. 1, 'PRISMA Flow diagram').

\section{Characteristics of participants and trials}

Characteristics of included trials are reported in Table 1, 'Summary of included trials'. The 11 included trials reported data from $n=2403$ participants $(n=1205$ intervention and 1198 control). The mean age ranged from 57 to 72 years. In all trials, stroke or TIA was clinically diagnosed in a hospital [28-38], and most had a mild stroke or TIA [28-31, 33-37], and enrolled in the trials after returning home [29-38]. There was a wide range in the sample sizes, ranging from 29 to 283 per trial arm. Most trials (73\%) targeted multiple risk factors without a specific focus on improving the levels of physical activity [29-33, 35, 37, 38]. Three trials $(27 \%)$ specifically targeted improving physical activity $[28,34,36]$.

All 11 interventions included a form of education, motivation and/or guidance to support the participants in changing their lifestyle. Regular supervised exercise was included in 2 of the trials that specifically targeted improving physical activity $[28,34]$, and on an ad hoc basis in the third [36]. In 3 of the included trials a physiotherapist was involved in the intervention [28, 36, 38]. In the other 7 trials the intervention was delivered by either a case manager, a general health care professional, a general practitioner, a nurse, an exercise practitioner, or it was not stated.

The type of outcome measures used to determine the level of physical activity varied. Only one trial used an objective outcome measure to measure steps and minutes spent in low, moderate and high intensity activity time per day [28]. The other 10 trials (91\%) used self-reported outcome measures [29-38]. Two trials used a standardized, validated questionnaire [34, 36], and 8 trials used general non-validated questionnaires [29-33, 35, 37, 38].

\section{Methodological quality}

The quality assessment of the included trials is reported in Table 2, 'PEDro scores'. Initial agreement among the 2 authors was $95 \%$ with full consensus reached through discussion. The PEDro scores ranged from 4 to 8 points (Table 2, 'PEDro scores'). No study achieved a full score of 10 points due to lack of blinding of the participants (question 5, supplementary Table S1, PEDro scale) and

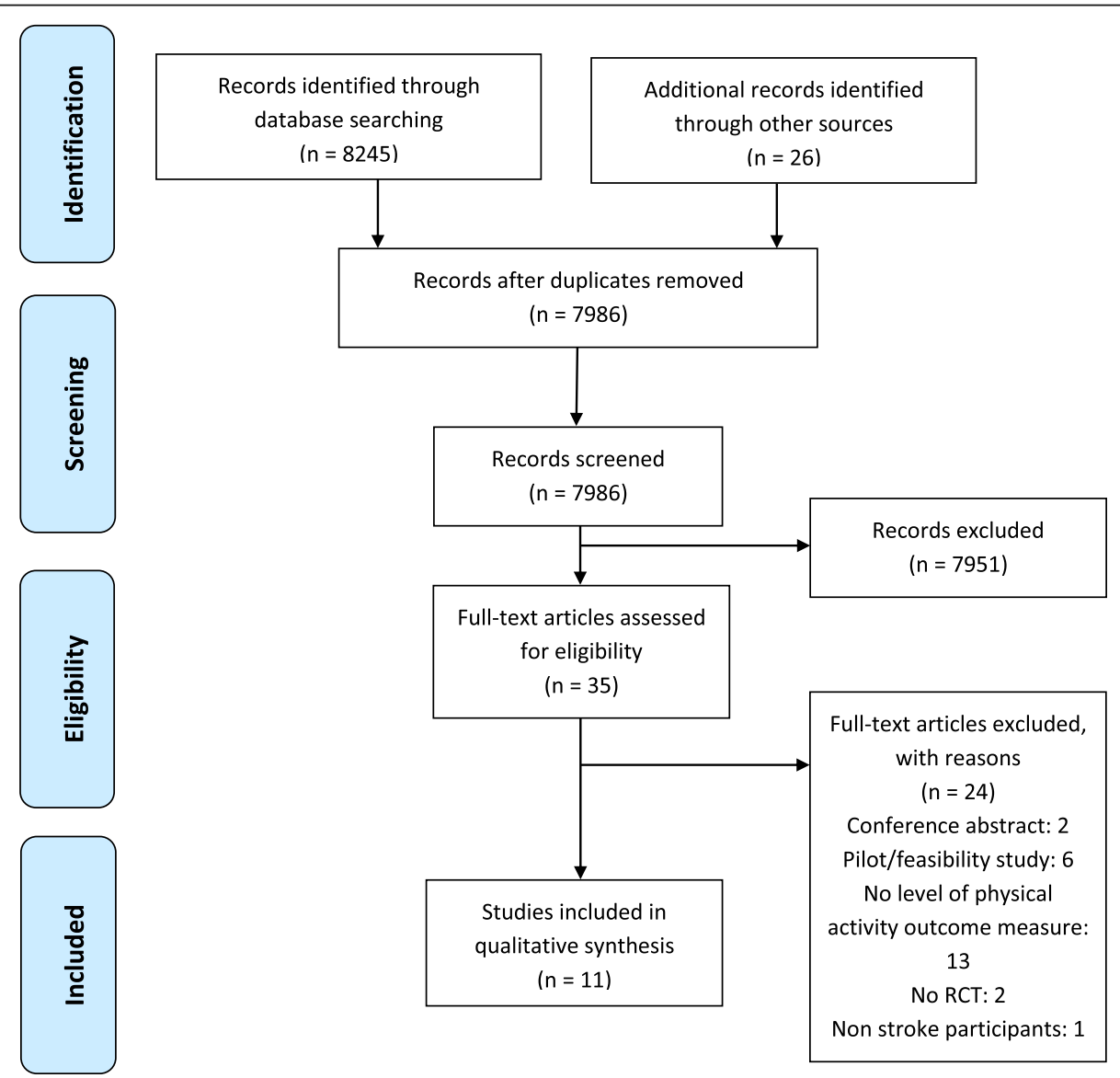

Fig. 1 PRISMA Flow diagram 


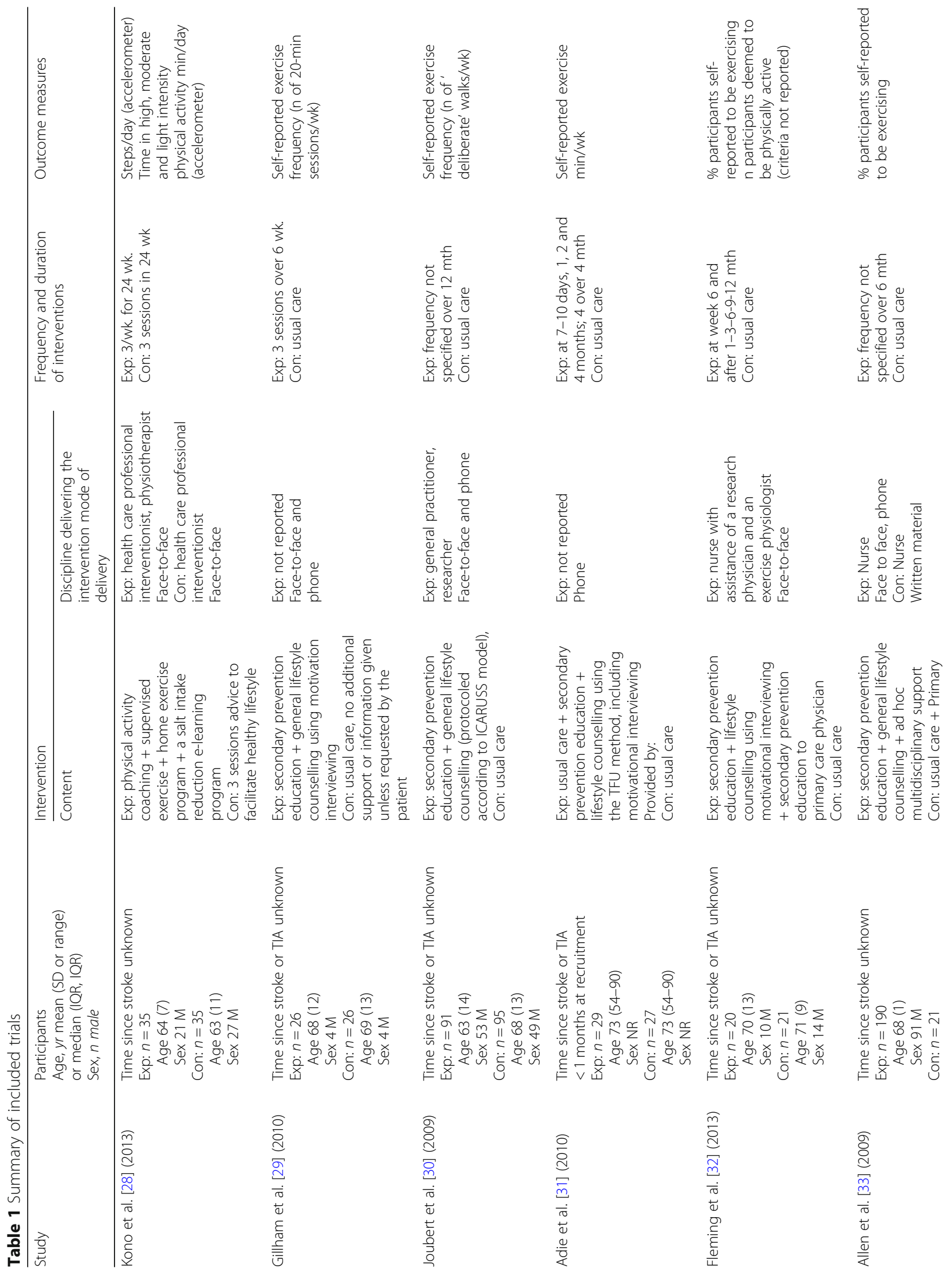









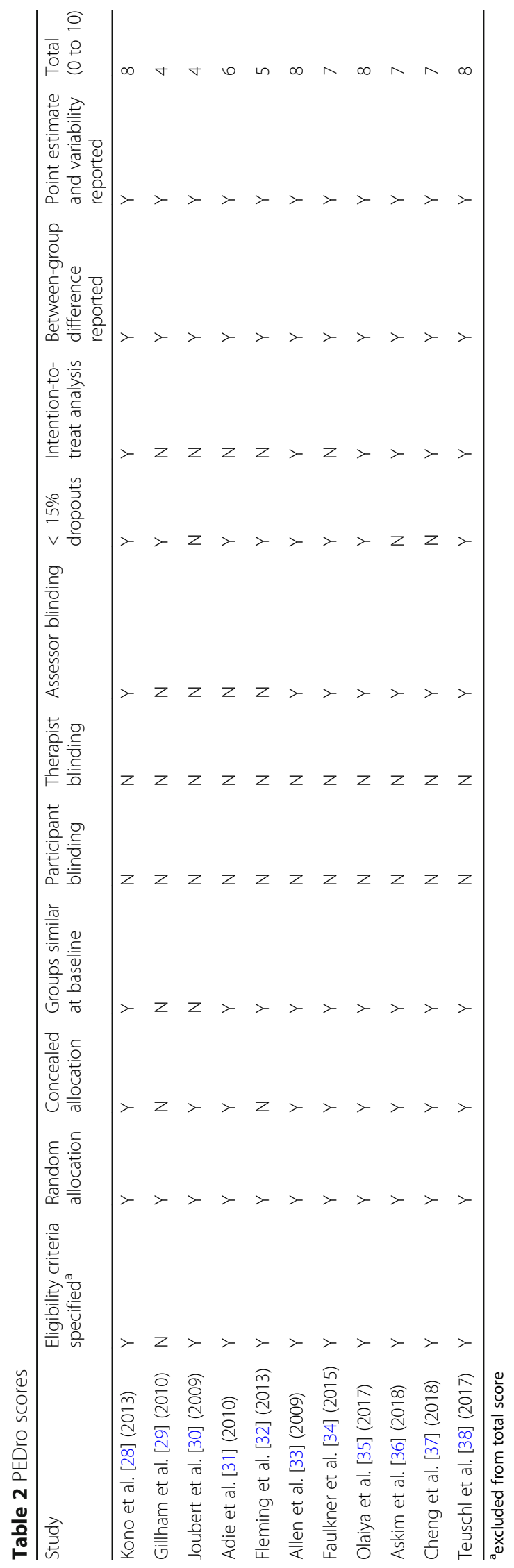


the professionals responsible for the treatment (question 6, supplementary Table S1, PEDro scale), which is not possible in these types of interventions. Eight studies had a score of 6 or higher and were therefore considered to be of high quality.

\section{Results of individual trials}

Five out of the 11 trials found significant differences in the level of physical activity in favour of the intervention [28-30, 32, 36]. The effect size of the intervention could be determined by calculating the SMD (see Table 3, 'Results individual studies') in three trials only [28-30], and this ranged from 0.29 to 0.98 .

As described above some of the trials specifically targeted improving physical activity levels and included either a standard or ad hoc supervised exercise component. Subgroup analyses of these 3 trials that included specific physical activity coaching and/or supervised exercise [28, $34,36]$, showed that 2 trials found a significant difference in the levels of physical activity in favour of the intervention $[28,36]$. For one of these trials the effect sizes of the intervention could be determined by calculating the SMD (see Table 3, 'Results individual studies'), which were 0.73 and 0.98 [28].

\section{Best evidence synthesis}

Based on PEDRO scores, 8 trials overall were considered to be of high quality and were included in the best evidence syntheses [28, 31, 33-38]. Two of these trials (25\%) found a significant difference in favour of the intervention [28,36], and 6 found (75\%) no significant between group difference [31, 33-35, 37, 38], therefore the domain of consistent findings ( $\geq 75 \%$, see methods) is met. The domain of precise data (see methods) is not met because in $38 \%$ of the trials the sample size was equal or below 35 for each treatment arm. Overall, this means there is moderate-quality evidence that lifestyle interventions do not lead to significant improvements in the level of physical activity in people with stroke or TIA, compared to usual care.

A subgroup best evidence synthesis including only trials with interventions that specifically targeted physical activity shows low quality evidence that such interventions are effective to improve the level of physical activity in people with stroke or TIA, compared to usual care. This is based on three high quality trials, of which two $(67 \%)$ found a significant difference in favour of the intervention $[28,36]$. One trial $(33 \%)$ found no significant between group difference [34], therefore the domain of consistent findings ( $\geq 75 \%$, see methods) is not met. The domain of precise data (see methods) is not met because in $67 \%$ of the trials the sample size was equal or below $n=35$ for each treatment arm.
When only general lifestyle interventions were included in a best evidence syntheses there was high quality evidence they do not lead to significant improvements in the level of physical activity in people with stroke or TIA, compared to usual care. Of the five high-quality trials included in this this analysis, all (100\%) show no significant between group difference $[31,33,35,37,38]$. This means that the domain of consistent findings ( $\geq 75 \%$, see methods) is met.

\section{Discussion}

This review found low-quality evidence that lifestyle interventions overall do not lead to significant improvements in the level of physical activity in people with stroke or TIA, compared to usual care, with only 2 (25\%) of the 8 high-quality trials demonstrating positive findings. The results of the subgroup analyses suggest that only lifestyle interventions that include specific strategies targeting physical activity have a positive effect on the levels of physical activity. However, sample sizes were small, and in the majority of trials the levels of physical activity was a secondary outcome measure. Therefore, it is possible that some of the included trials were insufficiently powered to determine the effectiveness of the interventions on physical activity.

Counselling, advice, education, support and encouragement were commonly incorporated into the interventions, however descriptions were sparse. In those trials that included general lifestyle counselling, details about the relative emphasis on physical activity was not provided. Therefore, there is limited information to guide clinical practice regarding lifestyle counselling or physical activity coaching to improve physical activity levels of people with stroke or TIA.

There were more consistent findings of benefit for trials that included specific physical activity coaching and/ or supervised exercise. The 2 high quality trials with significant positive findings included an exercise program as a standard part of their intervention or on an ad hoc basis $[28,36]$. However, one high quality trial that included an exercise program found no significant between group differences [34]. This study had a sample size of 29 participants per arm (compared to 35 and 186 in the other two), so might have been underpowered [34]. This suggests that including an exercise program in the lifestyle intervention may lead to better results. In 2 of the 3 high quality trials that specifically targeted improving physical activity $[28,36]$, a physiotherapist was involved in the intervention and both had positive findings $[28,36]$. Since a specific focus on physical activity and/or adding an exercise component to a lifestyle intervention might be beneficial, the involvement of experts in physical activity and exercise, such as physiotherapists may be a critical component for success. 










The outcome measures used across the included trials were too diverse to conduct meta-analyses in this review. This corresponds to the conclusions of earlier reviews [16-18]. All but one study included self-reported physical activity outcome measures. Additionally, several trials measured one aspect of physical activity (e.g. taking exercise walks or participating in exercise sessions), instead of all possible types of physical activity combined. These factors may have influenced the effect estimation. Without an overall, objective measure of physical activity definitive conclusions cannot be drawn. Further highquality research, using objective outcome measures, is needed. Our results on physical activity are in line with the recently updated Cochrane review on educational and behavioural interventions effects on physiological risk factors of recurrent stroke (e.g. blood pressure), which concluded these interventions did not lead to improvements in physiological risk factors [39].

\section{Limitations}

A meta-analysis was not possible and, though a best evidence synthesis was conducted, the limitations to sample sizes and the use of non-objective outcome measures still call for caution when interpreting the results. A systematic review on the use of different self-reported outcome measures of physical activity concluded that measurement properties were insufficiently addressed, specifically content validity [40]. Furthermore, the follow-up period was less than 2 months in 5 of the 8 high quality trials which limits the determination of sustainability of the effects.

The search strategy used was thorough and included three of the most commonly used databases. Though, it is always possible that due to the build of the search string, not including other databases and the exclusion of papers not published in English or Dutch, trials on the subject may not have been identified. We also acknowledge that since the search was conducted it is possible that additional trials have been published on the subject. Though a search in one database (Pubmed) in March 2020 did not reveal new studies.

All studies included in this review were conducted in high income countries [28-38]. However, the World Health Organisation concludes that the middle and lowincome countries have the highest incidence and death rates for stroke [1]. Further trials are needed to determine the effectiveness of lifestyle interventions in middle and low-income countries.

\section{Implications and recommendations for future research}

Current clinical guidelines emphasise the importance of increasing physical activity levels as part of (secondary) stroke prevention [12-15]. Clinicians therefore need clear guidance on the best way to improve physical activity levels for their patients. Although a positive trend is seen for trials that include specific physical activity coaching and/or supervised exercise programs, there is currently insufficient evidence to support definitive recommendations. There is also a lack of specific detail on the content and behaviour change techniques used in these interventions which further limits implementation. In light of the fact that sustainable behaviour change has been proven very difficult both in research and clinical practice, this information is crucial [41, 42]. Recommendations for further research include better description of the content of the intervention in particular the behaviour change techniques used, more homogeneous objective outcome measures, adequate sample sizes, and longer follow-up periods [43]. Populations from middle and low income countries should also be included.

\section{Conclusion}

The results of this review demonstrate high-quality evidence that general lifestyle interventions seem insufficient to improve the levels of physical activity in people with stroke or TIA. The subgroup analyses indicate that lifestyle interventions specifically targeting the levels of physical activity might be effective. Further research is needed to determine the effectiveness of combining lifestyle interventions that include behaviour change strategies specifically focusing on improving physical activity and/or supervised exercise programs to sustainably improve physical activity after stroke.

\section{Supplementary information}

Supplementary information accompanies this paper at https://doi.org/10. 1186/s12883-020-01730-3.

Additional file 1. Appendix I Search strategy.

Additional file 2: Table S1. PEDro scale.

\section{Abbreviations}

CINAHL: Cumulative Index for Nursing and Allied Health Literature; GRADE: Grading of Recommendations, Assessment, Development and Evaluations; PEDro: Physiotherapy Evidence Database; PRISMA: Preferred Reporting Items for Systematic Reviews and Meta-analyses; PROSPERO: International Prospective Register of Systematic Reviews; RCT: Randomised clinical trial; SMD: Standardized mean difference; TIA: Transient Ischemic Attack

\section{Acknowledgements}

We want to thank Gary Crowfoot (Hunter Medical Research Institute, Newcastle Australia), Gillian Mason (Hunter Medical Research Institute, Newcastle Australia) and Dawn Simpson (University of Newcastle, Newcastle Australia) for their input on the manuscript.

\section{Authors' contributions}

Research questions and design: WH, LV, KV, RW, CV, CE and MFP. Inclusion of articles, quality appraisal and data extraction: WH, LV and MFP. Analyses, interpreting results and drafting of the manuscript: WH, LV, KV, RW, CV, CE and MFP. All authors have read and approved the manuscript: WH, LV, KV, RW, CV, CE and MFP. 


\section{Funding}

This research did not receive any specific grant from funding agencies in the public, commercial, or not-for-profit sectors.

\section{Availability of data and materials}

The current study was a systematic review and all data used was retrieved from the published articles of the included studies and their supplementary material. Therefore, all data is available from those published papers and supplementary material.

\section{Ethics approval and consent to participate}

Not applicable since this is a systematic review.

\section{Consent for publication}

Not applicable since no details, images, or videos relating to an individual person are included in the manuscript. Approval has been obtained for those listed in the Acknowledgements section.

\section{Competing interests}

The authors declare that they have no competing interests.

\section{Author details}

'Department of Rehabilitation, Physiotherapy Science \& Sport, UMC Utrecht Brain Center, University Medical Center Utrecht, Utrecht University, Utrecht, The Netherlands. ${ }^{2}$ Center for Physical Therapy Research and Innovation in Primary Care, Julius Health Care Centers, Emile Hullebroeckstraat 60, 3543 BZ Utrecht, The Netherlands. ${ }^{3}$ Department of Medicine, Dunedin School of Medicine and School of Physiotherapy, University of Otago, Dunedin, New Zealand. ${ }^{4}$ Department of Health Innovations and Technology, Fontys University of Applied Sciences, Eindhoven, The Netherlands. ${ }^{5}$ Innovation for Human Movement Care Research Group, HU University of Applied Sciences, Utrecht, The Netherlands. ${ }^{6}$ School of Health Sciences and Priority Research Centre for Stroke and Brain Injury, University of Newcastle, Newcastle, Australia. ${ }^{7}$ Centre for Research Excellence in Stroke Recovery and Rehabilitation, Florey Institute of Neuroscience and Hunter Medical Research Institute, Newcastle, Australia.

Received: 9 July 2019 Accepted: 15 April 2020

Published online: 01 May 2020

\section{References}

1. $\mathrm{WHO}$ | Global atlas on cardiovascular disease prevention and control. WHO. 2015.

2. Mohan KM, Wolfe CDA, Rudd AG, Heuschmann PU, Kolominsky-Rabas PL, Grieve AP. Risk and cumulative risk of stroke recurrence: a systematic review and meta-analysis. Stroke. 2011;42:1489-94. https://doi.org/10.1161/ STROKEAHA.110.602615.

3. Burn J, Dennis M, Bamford J, Sandercock P, Wade D, Warlow C. Long-term risk of recurrent stroke after a first-ever stroke. Oxfordshire Community Stroke Project Stroke. 1994;25:333-7.

4. Furie KL, Kasner SE, Adams RJ, Albers GW, Bush RL, Fagan SC, et al. Guidelines for the prevention of stroke in patients with stroke or transient ischemic attack: a guideline for healthcare professionals from the American Heart Association/American stroke association. Stroke. 2011;42:227-76 http://www.embase.com/search/results?subaction=viewrecord\&from= export\&id=L51121482.

5. European Stroke Organisation (ESO) Executive Committee, ESO Writing Committee. Guidelines for Management of Ischaemic Stroke and Transient Ischaemic Attack 2008. Cerebrovasc Dis. 2008;25:457-507. https://doi.org/10. 1159/000131083.

6. Billinger SA, Arena R, Bernhardt J, Eng JJ, Franklin BA, Johnson CM, et al. Physical activity and exercise recommendations for stroke survivors: a statement for healthcare professionals from the American Heart Association/American Stroke Association. Stroke. 2014;45:2532-53. https:// doi.org/10.1161/STR.0000000000000022.

7. American Heart Association Recommendations for Physical Activity in Adults and Kids | American Heart Association. https://www.heart.org/en/ healthy-living/fitness/fitness-basics/aha-recs-for-physical-activity-in-adults. Accessed 13 Mar 2020.
8. World Health Organization. Global recommendations on physical activity for health. World Health Organization. 2010. https://apps.who.int/iris/handle/1 0665/44399. Accessed 13 Mar 2020.

9. Paul L, Brewster S, Wyke S, Gill JMR, Alexander G, Dybus A, et al. Physical activity profiles and sedentary behaviour in people following stroke: a crosssectional study. Disabil Rehabil. 2016;38:362-7. https://doi.org/10.3109/ 09638288.2015.1041615

10. Butler EN, Evenson KR. Prevalence of physical activity and sedentary behavior among stroke survivors in the United States. Top Stroke Rehabil. 2014;21:246-55. https://doi.org/10.1310/tsr2103-246.

11. Fini NA, Holland AE, Keating J, Simek J, Bernhardt J. How physically active are people following stroke? Systematic review and quantitative synthesis. Phys Ther. 2017;97:707-17. https://doi.org/10.1093/ptj/pzx038.

12. Stroke Foundation. Clinical Guidelines for Stroke Management 2017. Stroke Found Melb Aust 2017. https://informme.org.au/en/Guidelines/ClinicalGuidelines-for-Stroke-Management-2017.

13. Rudd AG, Bowen A, Young GR, James MA. The latest national clinical guideline for stroke. Clin Med (Northfield II). 2017;17:154-5. https://doi.org/ 10.7861/clinmedicine.17-2-154.

14. Wein T, Lindsay MP, Cote R, Foley N, Berlingieri J, Bhogal S, et al. Canadian stroke best practice recommendations: secondary prevention of stroke, sixth edition practice guidelines, update 2017. Int J Stroke. 2018;13:420-43.

15. Koninklijk Nederlands Genootschap voor Fysiotherapie. KNGF-richtlijn Beroerte. 2014. www.kngfrichtlijnen.nl.

16. Lennon O, Galvin R, Smith K, Doody C, Blake C. Lifestyle interventions for secondary disease prevention in stroke and transient ischaemic attack: a systematic review. Eur J Prev Cardiol. 2014;21:1026-39.

17. Lawrence M, Pringle J, Kerr S, Booth J, Govan L, Roberts NJ. Multimodal secondary prevention behavioral interventions for TIA and stroke: a systematic review and meta-analysis. PLoS One. 2015;10:e0120902.

18. Deijle IA, Van Schaik SM, Van Wegen EEH, Weinstein HC, Kwakkel G, Van den Berg-Vos RM. Lifestyle interventions to prevent cardiovascular events after stroke and transient ischemic attack: systematic review and metaanalysis. Stroke. 2017;48:174-9. https://doi.org/10.1161/STROKEAHA.116. 013794.

19. Moher D, Liberati A, Tetzlaff J, Altman DG. Preferred reporting items for systematic reviews and meta-analyses: the PRISMA statement. BMJ. 2009; 339(1):b2535. https://doi.org/10.1136/bmj.b2535.

20. PEDro scale (English). http://www.pedro.org.au/english/downloads/pedroscale/. Accessed 10 Aug 2018.

21. Teasell R, Foley N, Salter K, Bhogal S, Jutai J, Speechley M. Evidence-based review of stroke rehabilitation: executive summary, 12th edition. Top Stroke Rehabil. 2009;16:463-88. https://doi.org/10.1310/tsr1606-463.

22. Furlan AD, Pennick V, Bombardier C, van Tulder M. Editorial Board, Cochrane Back Review Group. 2009 Updated Method Guidelines for Systematic Reviews in the Cochrane Back Review Group. Spine (Phila Pa 1976). 2009;34: 1929-41. https://doi.org/10.1097/BRS.0b013e3181b1c99f.

23. Cochrane Handbook for Systematic Reviews of Interventions / Editorial and Publishing Policy Resource | Cochrane Community. https://community. cochrane.org/editorial-and-publishing-policy-resource/cochrane-reviewdevelopment/cochrane-handbooks/cochrane-handbook-systematic-reviewsinterventions. Accessed 26 Sep 2018.

24. Guyatt GH, Oxman AD, Kunz R, Vist GE, Falck-Ytter $Y$, Schünemann HJ, et al, What is \&quot;quality of evidence\&quot; and why is it important to clinicians? BMJ. 2008;336:995-8. https://doi.org/10.1136/bmj.39490.551019.BE.

25. Guyatt GH, Oxman AD, Vist GE, Kunz R, Falck-Ytter Y, Alonso-Coello P, et al. GRADE: an emerging consensus on rating quality of evidence and strength of recommendations. BMJ. 2008;336:924-6. https://doi.org/10.1136/bmj. 39489.470347.AD.

26. Rosenthal R. The handbook of research synthesis. In: Cooper H, Hedges $L$, editors. The handbook of research synthesis. New York: Russell Sage Foundation; 1994. p. 231-44.

27. Cohen J. Statistical power analysis for the behavioural sciences. 2nd edition. Lawrence Erlbaum Associates; 1988.

28. Kono Y, Yamada S, Yamaguchi J, Hagiwara Y, Iritani N, Ishida S, et al. Secondary prevention of new vascular events with lifestyle intervention in patients with noncardioembolic mild ischemic stroke: a single-center randomized controlled trial. Cerebrovasc Dis. 2013;36:88-97.

29. Gillham S, Endacott R. Impact of enhanced secondary prevention on health behaviour in patients following minor stroke and transient ischaemic attack: a randomized controlled trial. Clin Rehabil. 2010;24:822-30. 
30. Joubert J, Reid C, Barton D, Cumming T, McLean A, Joubert L, et al. Integrated care improves risk-factor modification after stroke: initial results of the integrated Care for the Reduction of secondary stroke model. J Neurol Neurosurg Psychiatry. 2009:80:279-84. https://doi.org/10.1136/jnnp. 2008.148122.

31. Adie K, James MA. Does telephone follow-up improve blood pressure after minor stroke or TIA? Age Ageing. 2010;39:598-603.

32. Flemming KD, Allison TG, Covalt JL, Herzig DE, Brown RD. Utility of a posthospitalization stroke prevention program managed by nurses. Hosp Pract (1995). 2013;41:70-9.

33. Allen K, Hazelett S, Jarjoura D, Hua K, Wright K, Weinhardt J, et al. A randomized trial testing the superiority of a postdischarge care management model for stroke survivors. J Stroke Cerebrovasc Dis. 2009;18 443-52.

34. Faulkner J, McGonigal G, Woolley B, Stoner L, Wong L, Lambrick D. A randomized controlled trial to assess the psychosocial effects of early exercise engagement in patients diagnosed with transient ischaemic attack and mild, non-disabling stroke. Clin Rehabil. 2015;29:783-94.

35. Olaiya MT, Kim J, Nelson MR, Srikanth VK, Bladin CF, Gerraty RP, et al. Effectiveness of a shared team approach between nurses and doctors for improved risk factor management in survivors of stroke: a cluster randomized controlled trial. Eur J Neurol. 2017:24:920-8. https://doi.org/10 1111/ene.13306.

36. Askim T, Langhammer B, Ihle-Hansen H, Gunnes M, Lydersen S, Indredavik B. Efficacy and safety of individualized coaching after stroke: the LAST study (life after stroke). Stroke. 2018:49:426-32. https://doi.org/10.1161/ STROKEAHA.117.018827.

37. Cheng EM, Cunningham WE, Towfighi A, Sanossian N, Bryg RJ, Anderson TL, et al. Efficacy of a chronic care-based intervention on secondary stroke prevention among vulnerable stroke survivors: a randomized controlled trial. Circ Cardiovasc Qual Outcomes. 2018;11:e003228. https://doi.org/10.1161/ CIRCOUTCOMES.116.003228.

38. Teuschl Y, Matz K, Firlinger B, Dachenhausen A, Tuomilehto J, Brainin M, et al. Preventive effects of multiple domain interventions on lifestyle and risk factor changes in stroke survivors: evidence from a two-year randomized trial. Int J Stroke. 2017;12:976-84. https://doi.org/10.1177/ 1747493017702662.

39. Bridgwood B, Lager KE, Mistri AK, Khunti K, Wilson AD, Modi P. Interventions for improving modifiable risk factor control in the secondary prevention of stroke. Cochrane Database Syst Rev. 2018. https://doi.org/10.1002/14651858. CD009103.pub3.

40. Martins JC, Aguiar LT, Nadeau S, Scianni AA, Teixeira-Salmela LF, Faria CDCDM. Measurement properties of self-report physical activity assessment tools for patients with stroke: a systematic review. Brazilian J Phys Ther. 2019;23:476-90. https://doi.org/10.1016/j.bjpt.2019.02.004

41. Michie S, Atkins L, West R. The Behaviour Change Wheel, a guide to designing interventions. London: Silverback Publishing Greate Brintain; 2014

42. Michie S, van Stralen MM, West R. The behaviour change wheel: a new method for characterising and designing behaviour change interventions. Implement Sci. 2011;6:42. https://doi.org/10.1186/1748-5908-6-42.

43. Kwakkel G, Lannin NA, Borschmann K, English C, Ali M, Churilov L, et al. Standardized measurement of sensorimotor recovery in stroke trials: consensus-based core recommendations from the stroke recovery and rehabilitation roundtable. Int J Stroke. 2017;12:451-61. https://doi.org/10 1177/1747493017711813.

\section{Publisher's Note}

Springer Nature remains neutral with regard to jurisdictional claims in published maps and institutional affiliations.

Ready to submit your research? Choose BMC and benefit from:

- fast, convenient online submission

- thorough peer review by experienced researchers in your field

- rapid publication on acceptance

- support for research data, including large and complex data types

- gold Open Access which fosters wider collaboration and increased citations

- maximum visibility for your research: over $100 \mathrm{M}$ website views per year

At $\mathrm{BMC}$, research is always in progress.

Learn more biomedcentral.com/submissions 